\title{
ACTION PENDING: FOUR YEARS ON FROM THE NEW ZEALAND SIGN LANGUAGE ACT 2006
}

\author{
Rachel Locker McKee*
}

\begin{abstract}
The granting of official language status to New Zealand Sign Language (NZSL) through the New Zealand Sign Language Act 2006 (NZSL Act 2006) is unusual in terms of the status of signed languages around the world. Many governments have accorded various forms of recognition to a signed language, but no others appear to have granted it official language status. ${ }^{1}$ Language policy makes and promotes certain choices about language use at a particular socio-historical moment; such decisions thus have social and political meaning to the minority community and to wider society. ${ }^{2}$ What motivated the government to recognise NZSL as an official language, and what has been achieved by it? Did cross-party support for this Act signal societal commitment to linguistic diversity and equity? Or did the negligible material implications of the Act ensure its approval by politicians as a compensatory gesture towards a disadvantaged community? This article critically examines the aims, provisions, and impacts of the NZSL Act 2006, and reports data from two recent surveys of stakeholders about priorities for further action to realise the purpose of the Act.
\end{abstract}

\section{WHY IS SIGN LANGUAGE RECOGNITION NEEDED?}

Language planning has been described as "deliberate decision making in response to language problems". ${ }^{3}$ The status of sign language users through history has been closely bound to how

* Sections of this article are reproduced from an earlier publication that appeared in the Journal of New Zealand Studies (see R McKee "The Eyes Have it! Our Third Official Language - New Zealand Sign Language" (2005-2006) 4/5 Journal of New Zealand Studies 129). I am grateful to the editor of the Journal of New Zealand Studies for permission to re-publish that material within the current article.

1 T Reagan "Language Policy and Sign Languages" in TK Ricento (ed) An Introduction to Language Policy Theory and Method (Blackwell Publishing, Malden, 2006) 329; World Federation of the Deaf "Status of Sign Language in Legislation" (2007) World Federation of the Deaf <www.wfdeaf.org>.

2 Claire Ramsey "Language planning in Deaf education" in Ceil Lucas (ed) The Sociolinguistics of the Deaf Community (Academic Press Inc, San Deigo, 1989) 123 at 124.

3 Ibid. 
education systems have responded to the problem of deaf children achieving access to language, education and acculturation into society. Almost universally, deaf people have been subject to language ideology and associated pedagogy controlled by non-deaf authorities, with scant reference to their own collective experience. These pedagogies tend to polarise acceptance of sign language as an effective visual medium for learning on the one hand, and an oralist approach that rejects signing and promotes speech as the socially normative mode of communication, on the other. The balance of institutional power has been firmly with oralism in New Zealand. ${ }^{4}$ But facility in the dominant spoken/written language (and the social capital this affords) remains elusive for many people who have a severe or profound hearing impairment from early childhood, and a visual-gestural language is a default cultural adaptation. ${ }^{5}$ The stigma associated with sign language, however, and the limited success of oralist education (practised in New Zealand until the 1980s), positions sign language users as culturally and linguistically marginalised in many societies. ${ }^{6}$ Refell ${ }^{7}$ argues that deaf people and immigrants who do not yet speak the majority language effectively share a disempowered status as "margizens", by virtue of their limited capacity to exercise citizenship rights. ${ }^{8}$

Modern threats to the survival of signed languages and their communities in Western societies include mainstreaming as the dominant mode of special education (which interrupts transmission of sign language between cohorts of deaf peers), cochlear implants as a first response to infant deafness, and genetic bio-technology aimed at eliminating hereditary deafness. ${ }^{9}$ All of these factors are present in New Zealand, and affect the future of the NZSL community.

4 W Forman "Toward a critique of the exclusive use of oral methods in education of the Deaf" (2000) 7 New Zealand Journal of Disability 40; L Monaghan "Signing, Oralisim and the Development of the New Zealand Deaf Community: An Ethnology and History of Language Ideologies" (Doctoral Dissertation, University of California, 1996); S Townshend "'The Hands just have to Move': Deaf Education in New Zealand - a Perspective from the Deaf Community" (Masters Thesis, Massey University, 1993).

5 C Padden and T Humphries Deaf in America: Voices from a Culture (Harvard University Press, Cambridge, 1988).

6 D Baynton Forbidden signs: American Culture and the Campaign against Sign Language (University of Chicago Press, Chicago, 1996); Townshend, above n 4; P Ladd Understanding Deaf Culture; In Search of Deafhood (Multilingual Matters Ltd, Clevedon, 2003); H Lane When the Mind Hears: a History of the Deaf (Random House, New York, 1984); H Lane The Mask of Benevolence: Disabling the Deaf Community (Alfred A Knopf Publishers, New York, 1992); R McKee People of the Eye: Stories from the Deaf World (Bridget Williams Books Ltd, Wellington, 2001).

$7 \quad$ H Reffell Sign Language Legislation: A Comparative Analysis between New Zealand and Finland (Masters Thesis, University of Auckland, 2007).

8 For example, access to public services and civic life.

9 T Johnston "W(h)ither the Deaf Community? Population, Genetics, and the Future of Australian Sign Language" (2004) 148 American Annals of the Deaf 358. 
Against this backdrop, legal recognition of signed languages is therefore paramount on the deaf political agenda; the World Federation for the Deaf policy document, "Call for the Recognition of Sign Languages" invokes minority language rights in seeking national recognition of the indigenous languages of Deaf communities. ${ }^{10}$ Since the 1980s, critical deconstruction of the relationship between the suppression of sign languages and the social disadvantage of deaf people ${ }^{11}$ has underpinned Deaf activism. Recently, a growing number of countries have recognised the rights of sign language users through a variety of legislative and policy measures. In some cases, recognition simply acknowledges the linguistic status of a sign language and its community of users, while in others, instrumental rights to use sign language in particular domains are specified - typically in educational, legal and medical arenas. ${ }^{12}$ A report on the status of sign languages in Europe, for example, comments as follows: ${ }^{13}$

The question for governments is not anymore whether to recognise sign languages or not, but when and how to recognise sign languages. Finland and Portugal have recognised sign language (users) by amending their constitutions and enacting corresponding legislation. The French-speaking Community of Belgium, the Czech Republic, Denmark, Germany, Greece, Ireland, Italy, Lithuania, Norway, Poland, the Slovak Republic, Slovenia, Sweden, Switzerland and the United Kingdom have recognised sign language in acts and laws, often in relation to education or the profession of sign language interpreting.

While the protection of sign language is advocated in tandem with recognition of Deaf culture, ${ }^{14}$ the fundamental motive for recognising sign languages goes beyond valorising cultural-linguistic identity. More essentially, access to sign language - especially for children born deaf - arguably fulfils the right to communication itself, as a medium for the mental and social life fundamental to human existence and to productive citizenship. ${ }^{15}$ For sign language users, achieving linguistic rights is inseparable from realising basic human rights that follow from being able to communicate meaningfully in the family, at school and in civil society. Limits on such opportunities for users of an unrecognised sign language often result in the negative social outcomes familiar to colonised

10 Reagan, above $\mathrm{n} 1$, at 332-333.

11 See When the Mind Hears above n 6; The Mask of Benevolence, above n 6; O Wrigely The politics of deafness (Gallaudet University Press, Washington DC, 1996).

12 Reagan, above $\mathrm{n} 1$.

$13 \mathrm{~N}$ Timmermans A comparative analysis of the status of sign languages in Europe (Dutch Ministry of Health, Welfare and Sport 2003)

14 World Federation of the Deaf, above $\mathrm{n} 1$.

15 M Jokinen "The linguistic human rights of sign language users" in R Phillipson (ed) Rights to language: equity, power, and education. Celebrating the 60th birthday of Tove Skutnabb-Kangas (L Erlbaum Associates, Mahwah, 2000) 203 at 203; L Siegel "The argument for a constitutional right to communication and language" (2006) 6 Sign Language Studies 255. 
minorities, such as under-employment, under-participation in higher education, and reduced wellbeing. ${ }^{16}$

\section{DEVELOPMENT OF THE NZSL ACT}

Roots of the Act can be traced to the 1999 Labour Party manifesto, which promised a new ministerial portfolio for disability. ${ }^{17}$ This reflected an ideological acceptance of a social model of disability which asserts that disability is constructed by societal barriers, rather than being inherent in the physical impairments of individuals, and society therefore has an obligation to address those barriers at a structural level. By 1999, lobbying by the Deaf Association with support from the Disabled Persons Assembly about Deaf peoples' disadvantage in education and justice systems in particular, had led to a Labour party commitment to legally recognise NZSL. ${ }^{18}$ Subsequently, the New Zealand Public Health and Disability Act of 2000 mandated the New Zealand Disability Strategy, ${ }^{19}$ which has the objective of equalising social and economic participation for people with disabilities. For the Deaf community, accessible communication is central to achieving this objective.

The Office for Disability Issues (ODI) was established in 2002 to develop and monitor disability related policy and actions across government departments, in accordance with Disability Strategy objectives. In 2003, the ODI engaged in consultation with the national Deaf community as a first step towards developing a Bill that would fulfil Labour's manifesto promise and also address the objectives of the Disability Strategy. ${ }^{20}$ Three themes emerged from the community consultation: ${ }^{21}$

(i) Low awareness of Deaf people within the state sector and wider society;

(ii) Poor access to government services, and large discrepancies between the ways in which Deaf people and government agencies perceive the accessibility of government services for Deaf people;

(iii) Inadequate funding and development of sign language interpreter services.

16 P Dugdale Being Deaf in New Zealand: A Case Study of the Wellington Deaf Community (PhD Thesis, Victoria University of Wellington, 2000); Forman, above n 4; Ladd, above n 6; When the Mind Hears, above n 6; D Moskovitz and A Walton "Sign Language and Deaf Mana" (paper presented at the National Community Languages and TESOL Conference, Wellington, 1990).

17 A Wolf The New Zealand Sign Language Bill (Case Program) (The Australia and New Zealand School of Government, Parkville (Victoria), 2005).

18 Ibid.

19 The New Zealand Disability Strategy (Ministry of Health, 2001).

20 Wolf, above n 17.

21 Office for Disability Issues "History - New Zealand Sign Language Bill" (2006) Office for Disability Issues <www.odi.govt.nz>. 
Consultation findings gave direction for a draft Bill to address the Deaf community's dual aspiration for official recognition of their language and for better access to public services and information through NZSL.

The ensuing consultation with 27 government agencies on a draft proposal, however, revealed that "government agencies could not implement a Bill that moved very far from the status quo, because of resource limitations", and highlighted "difficulties in specifying enforceable rights or obligations with enough clarity to apply these in the myriad of circumstances in which they operated". ${ }^{22}$ In order to be both administratively and politically acceptable, the final form of the Bill specified enforceable rights only in legal proceedings and declared official recognition, without committing resources.

The Hon Ruth Dyson MP, Minister for Disability Issues at the time, introduced the New Zealand Sign Language Bill into parliament in April 2004. ${ }^{23}$ A large audience of Deaf people watched this first reading of the Bill which was simultaneously interpreted into NZSL and streamed live on the internet. ${ }^{24}$ The Justice and Electoral Select Committee considered public submissions later in 2004, a process which raised consciousness on both sides: instructions for submitters were made available in NZSL web clips by the ODI, and the committee received submissions in writing and in NZSL on videotape, as English is not the first language of many NZSL users. Hearing the presentations of Deaf submitters required arranging sign language interpreters and videoconferencing to make proceedings accessible to all participants. During subsequent parliamentary debates, members of the Select Committee remarked on the impact of this experience on their understanding of what it means to facilitate access and inclusion for sign language users. For the Deaf community, this was the first time that they had been directly involved in - and enabled to access - the legislative process; it was an empowering experience to articulate their experiences and aspirations directly to the highest level of state authority in their own language.

Analysis of written and oral submissions on the Bill reveals four main motives for supporting recognition:

(i) restoring esteem to NZSL users through linguistic and cultural recognition (reversing the harm suffered through stigmatisation of sign language);

(ii) securing and implementing the right to access public services and information through NZSL, and also improving communication access in areas that fall outside state funded services (broadcasting or employment, for example);

22 Wolf, above $\mathrm{n} 17$, at 3 .

23 New Zealand Sign Language Bill (2004) (124-1); Office for Disability Issues, above n 21.

24 Ibid. 
(iii) making compulsory education available through NZSL, as of right, to Deaf children; and

(iv) material support for the maintenance and promotion of NZSL, both within Deaf community domains and by encouraging the wider community to use NZSL (effectively increasing Deaf people's inclusion in society). In its report to Parliament, the Select Committee acknowledged that it could not address all of these concerns within its recommended amendments to the Bill, which ultimately remained close to its draft form presumably constrained by the knowledge that adding resource implications to the legislation would hinder its passage and capacity to be implemented.

In its report to Parliament, the Select Committee acknowledged that it could not address all of these concerns within its recommended amendments to the Bill, which ultimately remained close to its draft form - presumably constrained by the knowledge that adding resource implications to the legislation would hinder its passage and capacity to be implemented.

Objections to the Bill during submissions and readings in the House raised the issue of creating inequitable privilege by according special rights to one language group, and potentially opening the floodgates to similar demands by immigrant communities. An analysis of the consistency of the NZSL Bill with the New Zealand Bill of Rights Act 1990 by the ministry of Justice concluded that it did not impinge on the rights or freedoms conferred by any previous legislation, nor privilege NZSL users over any others. ${ }^{25}$ The Act also states that recognition is premised on NZSL having no other home country, in effect being endemic to New Zealand.

A second counter-argument raised was that government support would be better directed towards more medical and technological interventions to prevent and remediate the limitations created by hearing impairment. Drafters and advocates of the Bill would consider this view to be irrelevant, as the Deaf community's aim in advocating for legal recognition was to seek validation, not rehabilitation, of their linguistic identity, a perspective that was clearly understood by the majority of MPs responding to the Bill. This reasoning is also spurious in that the legislation was clearly not committing any funding that might alternatively go towards vote health.

The third and most salient objection was the lack of an associated budget and the contingent risk of the law being merely symbolic - raising aspirations but not materially changing the status quo. Concerns about resourcing and practical measures were also expressed in submissions that supported the Bill. The Select Committee response was to indicate the role of policy in putting the principles of the Act into practice, and to recommend a review of its effect in three years time. Opposition MPs who queried the lack of budget in the House in 2006, are now in government and are thus better placed to rectify this.

25 A Fraser and V Sim Legal Advice: Consistency With The New Zealand Sign Language Bill of Rights Act 1990: New Zealand Sign Language Bill (Public Law Group Ministry of Justice, 2003). 
The NZSL Act was passed by 119 to 2 at its third reading on 6 April 2006, to a storm of handwaving and foot-stomping Deaf applause from the public gallery. Minister Dyson commented, at a celebratory function afterwards, on the powerful wave of emotion felt by all present in the House at that moment.

\section{PROVISIONS OF THE NZSL ACT}

Part 2 of the NZSL Act contains three main sections: Section 6 declares that NZSL is an official language of New Zealand. In this way the section recognises that NZSL is the first or preferred language of members of the Deaf community, and one that exists uniquely in New Zealand. Section 7 guarantees certain people the right to use NZSL in legal proceedings with the provision of competent interpreters, where it is the person's first or preferred language. Section 9 sets out principles that are to guide government departments to make their services accessible to NZSL users ("so far as reasonably practicable"). Additionally, s 13 enables regulations to be made that prescribe standards of competency for interpreters in legal proceedings, and on any other matters necessary to the administration of the Act.

The purpose of the Act was to address the uncertain legal status of NZSL and the structurally created social disadvantage that accrued to its users. ${ }^{26}$ The need to clarify the status of NZSL and its users arose from the fact that existing legislation did not explicitly afford protection from discrimination on the grounds of language. Analyses of the applicability of the NZ Bill of Rights Act and the Human Rights Act 1993 to language rights have concluded that language is subsumed as an aspect of race, ethnicity or national origin, while the ground of disability only offers indirect protection of the right to communicate in sign language. ${ }^{27}$ As Deaf people do not fit the definition of an ethnic minority, yet have suffered inequities as a result of linguistic discrimination, the NZSL Bill aimed to confer on NZSL a status equal to an indigenous spoken language, and further, to strengthen Deaf people's right to use that language in accessing public services. Although the Explanatory Note to the Bill commented that currently, "[p]rovisions for the use of NZSL interpreters are inadequate", no new rights or obligations were actually created in this respect; the right of individuals who do not understand English or Māori to interpretation in legal proceedings is already established through case law and statutes, ${ }^{28}$ and in customary practice. The NZSL Act alters the status quo only by identifying NZSL users as a class of people entitled to interpreting provision, alongside Māori speakers, and by requiring that interpreters be competent. Currently, competent is

26 See New Zealand Sign Language Bill 2004 (124-3) (Explanatory Note).

27 D Knight "Linguistic discrimination in education: the minority language speaker's right to meaningful education" (1996) 2 Human Rights Law and Practice 75; C Lane "Language and New Zealand Human Rights Law" (paper presented to the Language and Society Conference, University of Auckland, August 1998).

28 C Lane, K MacKenzie-Bridle and L Curtis "The Right to Interpreting and Translation Services in New Zealand Courts" (1999) 6 Forensic Linguistics 111. 
defined as holding the Diploma in Sign Language Interpreting, having at least two years of professional experience, and being a full member of the Sign Language Interpreters Association of New Zealand. ${ }^{29}$

\section{COMPARISON WITH THE MĀORI LANGUAGE ACT}

Like the Māori Language Act 1987, which "restores or compensates for losses", 30 the NZSL Act aims to remedy the fact that "Deaf New Zealanders have not been afforded the same right to their language as other New Zealanders" and have suffered serious disadvantage as a result. ${ }^{31}$ The provisions and wording of the NZSL Act draw closely upon those of the Māori Language Act. The table in the appendix of this article provides a comparative summary of the content of the two Acts. A key difference between the two Acts is the absence in the NZSL Act of the powers assigned to the Māori Language Commission to foster and regulate community and official uses of the language (s 6). Instead, the NZSL Act (s 9) enjoins government agencies to observe the principles of the Act in the delivery of their services and to consult with the Deaf community in doing so. Although mentioned in the regulation making provisions ( $\mathrm{s}$ 13), the NZSL Act also gives less direction regarding the administration of competency standards for legal interpreters. Finally, the NZSL Act lacks the provision of the Māori Language Act (s 14) to appropriate government funds for implementation. The Select Committee rationalised this significant difference as follows: ${ }^{32}$

We discussed with submitters the prospect of establishing a New Zealand Sign Language Commission, with functions similar to the Māori Language Commission ... We do not consider that a commission is necessary but at the same time we considered the establishment of an advisory group, which would have the role of monitoring the effects of the legislation against its stated purposes ... We consider this matter is better left to the Government to progress separately from this bill, but would recommend its serious consideration.

\section{MONITORING IMPLEMENTATION OF THE ACT}

The mechanism for monitoring implementation of the NZSL Act is indirect. Section 10 specifies that implementation may be monitored by the Minister via information in annual reports (of government bodies) on progress in implementing the New Zealand Disability Strategy, under the New Zealand Public Health and Disability Act 2000. Examination of the Disability Strategy

29 Ministry of Justice "Using New Zealand Sign Language In Court, English Courts 057" (2006) Ministry of Justice <www.justice.govt.nz>.

30 M Durie "Race and Ethnicity in Public Policy: Does it Work?" (2005) 24 Social Policy Journal of New Zealand 1.

31 New Zealand Sign Language Bill 2004 (123-1) (explanatory note) at 1.

32 New Zealand Sign Language Bill 2004 (123-2) (select committee report) at 5. 
Implementation Reports for $2007-2008^{33}$ by eight government ministries ${ }^{34}$ revealed that overall, little development of policy or other actions had been achieved, although some identified relevant future goals. Some reports stated that they will consider further actions "only as resources permit" (the Department of Corrections), during internal policy or review exercises in 2008-2011 (the National Library), or as "long term work". ${ }^{35}$ Some reports mention NZSL-related work not directly related to the NZSL Act (for example the Ministry of Education).

A December 2010 scan for the presence of NZSL on the public websites of twenty government ministries, agencies, and public bodies ${ }^{36}$ revealed a more visible public profile: all but one contained at least one reference to NZSL, in a range of forms including policy or practice statements, annual reporting on the Disability Strategy, reference to the use of interpreters, human interest stories about Deaf people, census data and in some cases, video clips presenting public information in NZSL. Most hits for "NZSL" in public sector websites are a brief or incidental mention. More substantive information about, or in, NZSL (clearly directed towards informing Deaf people and raising the profile of NZSL) was found in the websites of public sector organisations that have a focus on social service provision or equitable access. These included ODI, Workbridge, the Ministry of Health, the Ministry of Social Development, the Human Rights Commission, the Health and Disability Commission and Statistics NZ. These websites incorporate video files in NZSL, information about the right to use NZSL and in some cases links to Deaf-related sites. The websites of three major city councils, Auckland, Wellington and Christchurch all featured at least one mention of NZSL, mainly relating to provision of interpreters.

In relation to monitoring effectiveness, $\mathrm{s} 11$ of the Act states:

(1) The Minister must, as soon as is practicable, 3 years after the date on which this Act comes into force, require a report to be prepared on-

(a) the operation of this Act since its commencement; and

33 The most recent available.

34 Reports by the Ministries of Education, Health, Justice, and the Department of Corrections, Housing New Zealand, the National Library, the New Zealand Police and Statistics NZ. See Office for Disability Issues "Progress in Implementing the New Zealand Disability Strategy 2001 Implementation" Office for Disability Issues <www.odi.govt.nz>.

35 For example education regarding the provision of New Zealand Sign Language interpreters to children in schools.

36 Websites scanned were: Ministries of Justice, Health, Education, Social Development, Economic Development; Office for Disability Issues, NZ Police, Internal Affairs, Te Puni Kōkiri, ACC, Statistics NZ, Workbridge, Work and Income New Zealand, Corrections, Human Rights Commission, Health \& Disability Commission, Capital \& Coast Health, Wellington City Council, Auckland City Council, Christchurch City Council. 
(2) The Minister must ensure that persons or organisations that are representative of the interests of the members of the Deaf community are consulted on the matters to be considered in the report.

In 2010, ODI began work on developing the terms of a review, and community consultation on the effects of the Act is taking place in early 2011. ${ }^{37}$ Despite stakeholder hopes otherwise, it is widely expected that the scope of the review, will be narrow, given the current economic and social policy environment. Consultation on the Act is also likely to re-visit the original issues identified by consultation on the Bill, many of which were excluded from its scope but remain problematic for NZSL users.

\section{SYMBOLIC IMPACTS OF THE ACT}

Making NZSL an official language radically elevates its status to a par with English and Māori (in principle, at least), and validates the Deaf community's desire to maintain a distinct culturallinguistic identity - a fundamental minority linguistic right. ${ }^{38}$ The most immediately felt effect of the Act by the NZSL community is the symbolic, statutory acknowledgement of their status as a language community. This is a hard-fought shift in perception, as Deaf people have hitherto been positioned by mechanisms of policy, funding and service delivery within medical and education models that define and respond to deafness in terms of auditory impairment and individualised special needs. In relation to Māori social policy, Durie critiques needs-based solutions that centre on individuals and their socioeconomic status, without acknowledging the collective sociohistorical impacts of ethnicity and race on the group.

The Explanatory Note to the NZSL Bill also contests an individual needs or deficit model in its definition of NZSL users as a collective, stating: ${ }^{39}$

The capitalised "D" in "Deaf" is used internationally to denote a distinct linguistic and cultural group of people who are deaf and who use sign language as their first or preferred language, and includes those deaf people who identify with that group and with Deaf culture.

This change of frame around Deaf people's needs catches up with twenty years of identity politics in the Deaf world, and is also consistent with the 1992 proposal for a national languages policy which first positioned the Deaf community within a language planning framework. ${ }^{40}$

37 At the time of writing, December 2010.

38 S May "Language Policy and Minority Rights" in Thomas Ricento (ed) An Introduction to Language Policy: Theory and Method (Blackwell Publishing, Malden, MA, 2006) 255.

39 New Zealand Sign Language Bill (124-1) (explanatory note) at 1.

$40 \mathrm{~J}$ Waite Aoteareo: Speaking for Ourselves - Part B: The Issues (Ministry of Justice, 1992). 
Introducing a cultural-linguistic perspective on the Deaf community into the public discourse of social policy, to counterbalance the prevailing medicalised view, is an important outcome of the NZSL Act. The passage of the Act has increased the Deaf community's sense of political agency, providing moral leverage for engaging in rights-based lobbying for improved access to various domains of life. New Zealand's ratification of the United Nations International Convention on the Rights of People with Disabilities, which explicitly promotes the rights of sign language users, lends symbolic weight to the purpose of the NZSL Act and also imposes stronger obligations on the state to create instrumental rights. ${ }^{41}$ Progress on this front remains to be seen.

\section{SHORTCOMINGS OF THE ACT}

\section{A Consideration of Educational Linguistic Rights}

Changes to the status of a sign language are rarely effected without consideration of the impact on the education of Deaf children. Skutnabb-Kangas argues that: ${ }^{42}$

Educational linguistic human rights, especially the right to mother-tongue-medium education, are among the most important rights for any minority. Without them ... it cannot integrate, but is forced to assimilate.

With respect to educational linguistic rights, the NZSL Act does little to strengthen the promotion-oriented rights often associated with language planning for the education of linguistic minorities. ${ }^{43}$ This contrasts with sign language recognition measures in other countries in which education is the focal issue. Swedish Sign Language, for example, was legally recognised in 1981 specifically to mandate the provision of bilingual education for Deaf children, including support for their families to learn sign language from the time of diagnosis. Although this has not completely resolved educational under-achievement, the Swedish system is regarded as a strong educational linguistic rights model which recognises Deaf citizens as a linguistic minority for whom bilingualism is not only a legitimate social status but also an educational right. ${ }^{44}$ Norway, Finland and Uganda are among other nations that have recognised sign language as a rightful first language of Deaf children and provide substantial government resources for parent and child education in sign language from an early age.

41 Convention on the Rights of Persons with Disabilities GA Res A/Res/61/106 (2007).

42 T Skutnabb-Kangas "Language Policy and Linguistic Human Rights" in TK Ricento (ed) An Introduction to Language Policy - Theory and Method (Blackwell Publishing, Malden, 2006) 273 at 275.

43 S May Language and Minority Rights: Ethnicity, Nationalism and the Politics of Language (Pearson Education Ltd, Essex, 2001).

44 S Bagga-Gupta and L Domfors "Pedagogical Issues in Swedish Deaf Education" in L Monaghan, C Schmaling, K Nakamura and G Turner (eds) Many ways to be Deaf: International Variation in Deaf Communities (Gallaudet University Press, Washington DC, 2002) 67 at 67. 
In New Zealand, it is easier for an undergraduate student in Wellington or Auckland to learn NZSL for interest as part of their bachelor's degree than for the parents of a deaf pre-schooler to access regular tuition in NZSL to enable communication with their child. ${ }^{45}$ Similarly ironic, a deaf adult who has been charged with an offence and appears in court will have a qualified interpreter provided by law, whereas a deaf child who attends a mainstream school and relies on NZSL will most likely be provided with an untrained teacher aide who is expected to perform the work of an interpreter in facilitating access to education. ${ }^{46}$ Two formal human rights complaints challenging the unsatisfactory level of NZSL provision to deaf children are in progress at the time of writing. Similar cases recently won in Queensland and Victoria in Australia have obliged state governments to compensate claimants and to make substantial investment in training and services to enable the provision of Australian Sign Language within their education systems. ${ }^{47}$

Aspirations for educational linguistic rights, a core concern of the Deaf community, were sidestepped in the Select Committee report, which stated that: ${ }^{48}$

Many [submitters] recommended provision be made for the use of New Zealand Sign Language in

education. While we are sympathetic to submitters' concerns, we note that interdepartmental working

groups are working towards the development of long-term plans for the removal of language barriers for

the Deaf community in four priority areas: health, education, employment, and public broadcasting.

Removal of language barriers is a weaker and less measurable proposition than the establishment of a right or an obligation. Moreover, the import of language policy into the education system is qualitatively different than in areas such as employment or broadcasting. The use of sign language in education underpins both collective language maintenance and the realisation of individual human rights predicated on communication. Conflating these domains and delegating them to interdepartmental working groups portends a long road towards change. Few tangible outcomes from such processes have yet transpired.

45 P Laing "Migrating to a Deaf world: A model for understanding the experiences of hearing parents of deaf children" (2006) 3(1) Sites (News Series) 75; R McKee and E Smith Report on a Survey of Parents of 'High' and 'Very High Needs' Deaf Students in Mainstream Schools (Research Report 1, Deaf Studies Research Unit Research, Victoria University of Wellington, 2003); R McKee "Connecting hearing parents with the Deaf world" (2006) Sites (News Series) 3.

46 R McKee and E Smith Report on a Survey of Teachers Aides for 'High' and 'Very High Needs' Deaf Students in Mainstream Schools (Research Report 3, Deaf Studies Research Unit, Victoria University of Wellington, 2003).

47 L Komesaroff Disabling Pedagogy: Power, Politics and Deaf Education (Gallaudet University Press, Washington DC, 2008).

48 New Zealand Sign Language Bill 2004 (124-2) (select committee report) at 6. 


\section{B Language Maintenance and Promotion}

The NZSL Act does not address the need for language documentation, promotion and support of language teaching, which are key functions of the Commission created as a statutory body by the Māori Language Act. Public submissions and a consumer-based working group in the lead up to the Bill suggested a body with custodial and advisory responsibility for planning, promoting and monitoring functions. Politicians acknowledged but did not enact the idea: ${ }^{49}$

Several submitters commented on the need for ongoing and strategic funding to ensure that New

Zealand Sign Language can be effectively maintained and promoted. However we considered that there

was a need to monitor and report on the legislation before making any recommendations about funding.

This outcome reflects the reality that imposing financial and administrative burden on central government and its agencies would have undoubtedly hindered the passage of the Bill, although in relation to a national budget it seems unlikely to present an unsustainable cost. Connell ${ }^{50}$ points out in relation to legal claims for resources relating to te reo Māori, that:

The persistent argument, or justification, placed as a barrier to fulfilling the right to language is that economic constraints mean that a State is unable to make the promotion of minority languages a priority. In general, economic justifications as a sole justification for a limit are rarely received with favour by courts unless it would be a 'prohibitive' cost.

Comparison of the NZSL Act with legal recognition of Flemish Sign Language (VGT), also in 2006, highlights the omission of provisions for maintenance and promotion of the language. In Flanders, "recognition entails (1) a cultural (symbolic) recognition, (2) the foundation of a commission that will advise the Flemish government in all matters related to VGT and (3) the structural funding of research and development of VGT". ${ }^{51}$ This third measure is vital to supporting the status and potential dissemination of a suppressed language. Comparable sized nations Ireland ${ }^{52}$ and Finland ${ }^{53}$ both have state-funded bodies that have an advisory and strategic planning role on matters to do with sign language use, lexical development for new domains, and language teaching. Corpus and acquisition planning, which addresses language documentation, development and

49 Ibid at 5.

50 C Connell "The right to language and its contemporary significance for New Zealand" (LLM Research Paper, Victoria University of Wellington, 2006) at 24.

51 Reagan, above n 1.

52 L Leeson and T Lynch "Three Leaps of Faith and Four Giant Steps: Developing Interpreter Training in Ireland" in J Napier (ed) International Perspectives on Sign Language Interpreter Education (Gallaudet University Press, Washington DC, 2009) 35 at 35.

53 See Research Institute for the Languages of Finland "Homepage" Kotus <www.kotus.fi>. 
dissemination needs of a minority language, ${ }^{54}$ has been underway for 20 years at Victoria University in the form of lexicography, research on the structure, use and teaching of NZSL. ${ }^{55}$ NZSL teaching resources have also been developed at Auckland University of Technology and in the two Deaf education centres over this period. Linguistic description has been an important underpinning in the lobby for NZSL recognition, but this work has been dependent mainly upon soft funding sources, with little top-down planning.

\section{NZSL IN COURTS: A 2010 SURVEY OF SIGN LANGUAGE INTERPRETERS}

The one enforceable measure in the Act codifies the provision of NZSL interpreters in legal proceedings. To gain current perspective on the effects of this provision, the author surveyed qualified NZSL interpreters at the July 2010 conference of the Sign Language Interpreters Association of New Zealand (SLIANZ). Delegates were invited to complete a written questionnaire about their experiences relating to interpreting in legal proceedings since the passage of the NZSL Act. The purpose was to gather a national snapshot of practices around booking and use of NZSL interpreters in courts, from the interpreters' perspective. Gaining a Deaf consumer perspective on this is also critical, but the logistics of doing so are far more complex and was not possible within the available timeframe.

The questionnaire consisted of 11 multiple-choice questions and space for further comment. Questions canvassed interpreters' qualifications, their experience of bookings and work in courts and tribunals, and their awareness of un-met interpreting needs in their area. Participation in the survey was voluntary and anonymous. Forty interpreters completed the survey. The membership of SLIANZ is currently 65 , so the dataset represents approximately two-thirds of the membership, drawn from all main regions of New Zealand. During the conference, an oral discussion was also facilitated to elicit further relevant issues. Results are summarised below.

\section{A Compliance with Minimum Standard of Competence}

All 40 respondents were qualified by the Diploma of Sign Language Interpreting DipSLI or overseas equivalent: 37 currently hold ordinary (full) SLIANZ membership status, as required by the court regulations. Since 2006, three-quarters (30) of respondents had been asked to work in some type of court. One quarter (10) had not been requested to do so: 24 of the 40 respondents had

54 N Hornberger "Frameworks and Models in Language Policy and Planning" in TK Ricento (ed) An Introduction to Language Policy - Theory and Method (Blackwell Publishing, Malden, 2006) 24.

55 See M Collins-Ahlgren "Aspects of New Zealand Sign Language" (PhD Thesis, Victoria University of Wellington, 1989); P Dugdale, above n 16; G Kennedy and others (eds) A Dictionary of New Zealand Sign Language (Auckland University Press with Bridget Williams Books, Wellington, 1997); R McKee and D McKee New Zealand Sign Language Grammar: A Guide for Learners (Revised Version) (Deaf Studies Research Unit School of Linguistics and Applied Language Studies, Victoria University of Wellington, 2007). 
accepted assignments to interpret in a court or tribunal; 16 had not accepted court assignments, and/or not been asked. Court regulations following the Act specify that the minimum standard for interpreting in court is to hold the DipSLI and to have two years post-graduation experience. Accordingly, no interpreter qualified from 2008 onwards would be eligible to work in court at the time of the survey (July 2010). The four respondents who were qualified in 2008 or 2009 had indeed not been asked to do so. However, of the six interpreters qualified in 2007 (that is, just meeting the minimum two years experience threshold), five had been requested to work in courts, and three of them had undertaken several assignments.

The two-year undergraduate DipSLI is designed as entry-level preparation to work as a general community interpreter. Legal interpreting is considered by the wider interpreting profession to require additional linguistic, procedural and world knowledge, on top of a depth of interpreting experience. Notwithstanding variety in practitioners' skill levels and their pre-training backgrounds, it is not best practice to have recent graduates interpreting in high stakes environments such as legal proceedings. The fact that the minimum standard has been set at such a low level is a reflection of the lack of specialised training in this area in New Zealand, the scarcity of qualified interpreters, and perhaps an underestimation of the skills demanded in this type of work.

The 30 interpreters who had been asked to work in a court had been booked by a variety of parties, including interpreter booking agencies, courts, lawyers, Deaf individuals, and other individuals (such as family members or advocates).

Only three of the 24 interpreters who had worked in court had ever been directly asked to state or verify their qualification and experience (altogether four times). Two requests for verification came from a booking agency and two from a court. Twenty-one interpreters had never been asked to state or verify their qualification in relation to a court assignment. Several stated, though, that the agency that booked them was aware that they met the minimum requirements. In response to my query about court as opposed to agency responsibility for checking on qualifications, a major national sign language interpreter booking agency replied that a few courts are diligent in asking the agency about interpreters' credentials for court work, while the majority of court liaison staff do not enquire about the qualification of interpreters provided by the agency and some overtly request anyone available, willingly accepting unqualified individuals who work as interpreters in the community. 56

\section{B Specialised Training in Legal Interpreting}

The questionnaire asked: "Have you had formal training (beyond DipSLI) or professional development specific to legal interpreting?" Only six out of 40 reported having attended such training, and of these, four were short workshops (and one focused on police interviews rather than

56 Email communication from iSign Administrator to Rachel McKee regarding New Zealand Sign Language Interpreting in Courts (21 June 2010). 
court). Both of the respondents who had undertaken a course had done so in training designed for spoken language interpreters. The small proportion of interpreters who answered yes to this question reflects a lack of specialist training available for sign language interpreters at this stage of the profession's development and implies general under-preparation for work in the court context.

\section{Non-provision of Interpreters in Courts}

Although rarely in a position to directly witness it, interpreters often become aware of instances in which a Deaf person has appeared in court without an interpreter, sometimes because they are engaged to work at a subsequent stage of proceedings. The survey asked interpreters, "Do you know of any cases of Deaf people in your area appearing in court without an interpreter being provided?" 16 answered yes and 24 answered no. Reasons described for non-provision of an interpreter were as follows:

- Unqualified interpreter booked instead by the court.

- $\quad$ Court claimed no interpreters were available, although not all qualified interpreters in the area had been asked about the assignment.

- Genuine lack of interpreter availability.

- $\quad$ Court would not reschedule proceedings to allow time to book an interpreter.

- $\quad$ No show of a booked interpreter, so the appearance proceeded without one.

- $\quad$ Court decided an interpreter was not needed.

- $\quad$ Court was unaware that the person appearing was Deaf.

- $\quad$ Lawyer decided to proceed without interpreter, for reasons of timing.

- $\quad$ Court clerk forgot to book an interpreter for the appearance date.

Comments from respondents in discussion at the conference identified further problems and inconsistencies relating to interpreting in legal contexts. The key issues are summarised as follows:

- insufficient provision for interpreting in interactions preceding and following actual court proceedings,

- $\quad$ cost and availability of interpreter coverage in smaller centres,

- variable court staff knowledge and practices in booking of interpreters,

- interpreting provision for deaf family members of non-deaf defendants or victims,

- a need for higher level training, assessment and supervision of court interpreters,

- a need for training and use of deaf relay interpreters for clients with impaired language competence and 
- a need for well-defined and understood practice guidelines regarding working with sign language interpreters in courts.

Results of this brief survey indicate that by and large, courts (assisted by booking agencies through whom many court interpreters are contracted), are conforming to the required standard of competence for interpreters as specified in current regulations under the Act. Practitioner responses, however, suggest that the current threshold for qualification and training is lower than ideal; a number of interpreters who had declined to accept court assignments did so because they felt insufficiently skilled. Systemic problems with ensuring that interpreters are engaged when needed persist, and there remains an uncertain infrastructure around the employment and regulation of interpreters as a category of skilled professionals working in the justice system.

\section{COMMUNITY PRIORITIES FOR ACTION ON AN NZSL STRATEGY}

During 2009, key stakeholders in the NZSL community began discussing the idea of formulating a strategy to guide progress towards the aims of the NZSL Act. A small working group of individuals from the NZSL sector was facilitated by former Human Rights Commissioner, Robyn Hunt, to work towards this goal. ${ }^{57}$ The group looked to the previous Māori Language Strategy (2003) as a relevant model. The goals of that Strategy were to strengthen the following areas:

- $\quad$ language skills of Māori people;

- $\quad$ language use in Māori domains;

- opportunities to use/learn in Māori in education as a first or second language;

- community leadership for revitalization;

- $\quad$ societal recognition and support of Māori.

It was agreed that three key priorities should be identified as the focus of an initial five-year strategy for NZSL. In order to select these from a raft of issues already identified (in previous government consultations with the community), the group surveyed the views of NZSL user groups about their priorities for action on NZSL. From December 2009 to February 2010, a short survey was distributed via email to a wide network of individuals and groups in the following categories: Deaf community members; Deaf NZSL teachers; parents of deaf children; teachers and related professionals working with deaf children; sign language interpreters; and learners of NZSL.

57 The working group comprised members of the Human Rights Commission, Deaf Aotearoa New Zealand, New Zealand Sign Language Teachers Association, Deaf Studies Research Unit Victoria University (including the author), and the Sign Language Interpreters Association of New Zealand. The group had no official mandate or funding, nor formal representative structure; it was formed by individuals closely associated with the New Zealand Sign Language community who were motivated and able to contribute to this work. 
The survey was written in plain English and was also available in NZSL on the Deaf Aotearoa New Zealand website. It asked two questions:

(1) What are the three most important things that need to happen for NZSL? (Select 3, from a list of 9 possible priorities)

(2) If you have other ideas or issues that you want to share about how to make sure NZSL is supported, promoted and maintained in New Zealand, please tell us.

One hundred and forty responses were received between January and March 2010. The profile of respondents was as follows:

$\begin{array}{ll}\text { Deaf community } & 101 \\ \text { Parents of deaf children }^{58} & 10 \\ \text { NZSL students } & 10 \\ \text { Interpreters } & 9 \\ \text { Deaf education \& audiology professionals } & 5 \\ \text { Unidentified } & 4 \\ \text { Hearing Impaired } & 1\end{array}$

The top three NZSL Action priorities selected by respondents were:

Deaf children's access to education through NZSL 105 votes

Support for families/whanau to learn NZSL 69 votes

Interpreting services more available and better quality $\quad 48$ votes

The first and second priorities reflect significant concern across the sector about barriers to Deaf children and their families acquiring NZSL as a home language and the opportunity to use it as a medium for learning in the school system. These two related goals were supported equally strongly by Deaf community members, hearing parents of deaf children, and educators of deaf children who responded. The importance of these points is paramount in relation to achieving: (a) meaningful access to education (and better life outcomes) for deaf people from early childhood; and (b) the maintenance, transmission and natural growth of NZSL as a viable language in home, school and community contexts.

A need for expanded and more regulated interpreting services was identified as the next most important area for action. This reflects current constraints on the provision and funding of interpreting for Deaf people in many everyday domains, and the importance of interpreting

58 At least one parent responded on behalf of a group of parents. 
provision in actualising the human rights and potential of Deaf citizens. ${ }^{59}$ The survey indicates that action is needed on issues of interpreter workforce capacity, standards, funding entitlement, and service provision, as previously identified in a consultation report prepared prior to the NZSL Bill in $2004 .{ }^{60}$

Survey respondents also strongly supported the goal of promoting awareness, tolerance and visibility of NZSL in wider society.

Overall, survey responses reiterate priorities for action that have previously been articulated in community advocacy, government consultations and reports, and academic research on the status of NZSL users. Respondents expressed enthusiasm for the development of a formal strategy as a spur to action on realising the aims of the NZSL Act. The draft strategy is now available for public comment, ${ }^{61}$ but government buy-in to the concept and promotion of a strategy will need to be secured to turn it into a live document.

\section{CONCLUSION}

Consideration of the motives and development of the NZSL Act shows that it is predicated on a hybrid of human rights, disability rights and linguistic rights. Its main purpose and effect is to symbolically re-position NZSL users in the public discourse as a legitimate language community in New Zealand society. Daoust ${ }^{62}$ argues that "language-planning policies can best be evaluated through their symbolic impact (since ultimately) it is attitudes which lead to change". The NZSL Act authorises moral support for social justice for the Deaf community and sets a path for attitudinal change by promoting language recognition, without directly conferring new, instrumental rights that benefit NZSL users.

On the part of the Deaf community, engagement in the legislative process of language recognition has greatly increased their sense of political agency and pride. The achievement of official language status offers moral leverage and a heightened profile in Deaf people's interactions with the state and civil society. Moreover, the growing presence of NZSL and deaf awareness that is

59 R McKee "Interpreting as a Tool for Empowerment of the New Zealand Deaf Community" in S Fenton (ed) For better or worse; Translation as a tool for change in the South Pacific (St Jerome, Manchester, 2003) 89 at 89 .

60 Office for Disability Issues "New Zealand Sign Language Interpreter Issues: NZSL Interpreting in Court and Systems for Funding and Supply of Interpreter Services" (2004) Working Group on Interpreter Issues Report from Working Group on Interpreter Issues.

61 Available in English and New Zealand Sign Language "New Zealand Sign Language Strategy (Draft)".

62 D Daoust "Language Planning and Language Reform" in F Coulmans (ed) The Handbook of Sociolinguistics (Blackwell, Oxford, 1997) 436 as cited in GH Turner "Sign language planning: pragmatism, pessimism and principles" (2009) 10(3) Current Issues in Language Planning 243 at 244. 
now visible in a number of public sector websites provides encouraging evidence that the principles of the Act are taking effect in some quarters.

Deaf organisations have consistently lobbied for practical measures to improve their access to society, and to raise society's awareness of their entitlement to use sign language. ${ }^{63}$ Without an implementation strategy or resourcing, the NZSL Act itself is an impotent tool in building this bridge. Data from recent surveys of NZSL stakeholders reported in this article identify a call for action on persistent limitations on access to NZSL in the education and legal systems. The quality and availability of NZSL interpreting services are considered central to realising linguistic and human rights in these and other domains of citizenship. No resources or planning for promotion and maintenance of NZSL have flowed from the Act, which are essential to progressing the status and utility of the language to its users and to wider society.

63 P Dugdale Talking Hands, Listening Eyes: The History of the Deaf Association of New Zealand (The Deaf Association of New Zealand, Auckland, 2000); McKee, above n 59. 


\section{APPENDIX}

Comparison of the Māori Language Act 1987 and NZSL Act (paraphrased)

\begin{tabular}{|c|c|}
\hline Māori Language Act & NZSL Act \\
\hline $\begin{array}{l}\text { s } 3 \text { Māori declared to be an official language, } \\
\text { indigenous to New Zealand }\end{array}$ & $\begin{array}{l}\text { s } 6 \text { NZSL declared to be an official language, unique to } \\
\text { New Zealand }\end{array}$ \\
\hline s 4 Right to speak Māori in legal proceedings & $\begin{array}{l}\text { s } 7 \text { Right to use NZSL in legal proceedings, where it is a } \\
\text { person's preferred or first language }\end{array}$ \\
\hline $\begin{array}{l}\text { s 4(3) Presiding officer of the court must ensure that } \\
\text { a competent interpreter is available }\end{array}$ & $\begin{array}{l}\text { s 7(3) Presiding officer of the court must ensure that a } \\
\text { competent interpreter is available }\end{array}$ \\
\hline $\begin{array}{l}\text { s } 5 \text { Effect of recognition - does not effect existing } \\
\text { rights to communicate in Māori not specified in the } \\
\text { Act, nor the rights of any other linguistic community }\end{array}$ & $\begin{array}{l}\text { s } 8 \text { Effects of recognition - does not affect existing rights } \\
\text { to use NZSL, nor the rights of any other linguistic } \\
\text { community }\end{array}$ \\
\hline $\begin{array}{l}\text { s } 6 \text { Establishment of Māori Language Commission, } \\
\text { to - } \\
\text { (a) initiate, develop, co-ordinate, review, advise } \\
\text { upon, and assist in the implementation of } \\
\text { policies, procedures, measures, and practices } \\
\text { designed to give effect to the declaration in } \\
\text { section } 3 \text { of this Act of the Māori language as } \\
\text { an official language of New Zealand } \\
\text { promote the use of Māori language } \\
\text { (b) assess competency in the Māori language (re } \\
\text { (c) translation and interpreting) } \\
\text { to consider and report to the Minister upon } \\
\text { any matter relating to the Māori language } \\
\text { (e) other functions as may be conferred upon the } \\
\text { Commission by any other enactment }\end{array}$ & $\begin{array}{l}\text { s } 9 \text { A government department should, when exercising } \\
\text { its functions and powers, be guided, so far as reasonably } \\
\text { practicable, by the following principles: } \\
\text { - The Deaf community should be consulted on } \\
\text { matters that affect their language (NZSL) } \\
\text { NZSL should be used for the promotion of services } \\
\text { and information } \\
\text { Government information and services should be } \\
\text { accessible to Deaf people in different ways, } \\
\text { including NZLS } \\
\text { s } 10 \text { The Minister may from time to time report on the } \\
\text { progress being made in implementing the principles set } \\
\text { out in s } 9 \text {. (Reporting by government departments via } \\
\text { the reporting mechanism for the New Zealand Disability } \\
\text { Strategy.) }\end{array}$ \\
\hline $\begin{array}{l}\text { s } 14 \text { Money to be appropriated by Parliament for } \\
\text { purposes of Act - All fees, salaries, allowances, and } \\
\text { other expenditure payable or incurred under or in the } \\
\text { administration of Act shall be payable out of money } \\
\text { to be appropriated by Parliament for the purpose. }\end{array}$ & $\begin{array}{l}\text { NA } \\
\text { (Effects of the NZSL Act to be reviewed after three } \\
\text { years.) }\end{array}$ \\
\hline $\begin{array}{l}\text { s } 15 \text { Commission to grant certificates of competency } \\
\text { in the Māori language } \\
\text { - Qualification, certification of interpreters and } \\
\text { translators } \\
\text { Endorsement of interpreter and translator } \\
\text { certification of competence for purposes of } \\
\text { legal proceedings } \\
\text { Monitoring and disciplinary role - complaints } \\
\text { procedure }\end{array}$ & $\begin{array}{l}\text { s } 13 \text { Regulations: The Governor-General may make } \\
\text { regulations which prescribe standards of competency } \\
\text { required of NZSL interpreters in legal proceedings, and } \\
\text { regulations which determine assessment criteria relating } \\
\text { to standards. }\end{array}$ \\
\hline
\end{tabular}


